\title{
The melting level stability anomaly in the tropics
}

\section{Folkins}

Department of Physics and Atmospheric Science, Dalhousie University Halifax, B3H 3J5, Nova Scotia, Canada

Correspondence to: I. Folkins (ian.folkins@dal.ca)

Received: 9 February 2012 - Published in Atmos. Chem. Phys. Discuss.: 4 May 2012

Revised: 16 January 2013 - Accepted: 22 January 2013 - Published: 1 February 2013

\begin{abstract}
On short timescales, the effect of deep convection on the tropical atmosphere is to heat the upper troposphere and cool the lower troposphere. This stratiform temperature response to deep convection gives rise to a local maximum in stability near the melting level. We use temperature measurements from five radiosonde stations in the Western Tropical Pacific, from the Stratospheric Processes and their Role in Climate (SPARC) archive, to examine the response of this mid-tropospheric stability maximum to changes in surface temperature. We find that the height of the stability maximum increases when the surface temperature increases, by an amount roughly equal to the upward displacement of the $0{ }^{\circ} \mathrm{C}$ melting level. Although this response was determined using monthly mean temperature anomalies from an $10 \mathrm{yr}$ record (1999-2008), we use model results to show that a similar response should also be expected on longer timescales.
\end{abstract}

\section{Introduction}

The climatological temperature profile in the tropics exhibits three regions of enhanced stability: the top of the boundary layer $(\sim 2 \mathrm{~km})$, the melting level $(\sim 5 \mathrm{~km})$, and the tropopause $(\sim 16 \mathrm{~km})$. Within convective clouds, air parcels tend to lose buoyancy at heights where the background stability is enhanced. The three layers of increased stability are therefore associated with increased detrainment from boundary layer, cumulus congestus, and deep convective clouds, giving rise to the observed trimodal distribution of convective clouds in the tropics (Johnson et al., 1999). In this paper, we refer to the layer of anomalous stability near the melting level as the Melting Level Stability Anomaly (MLSA). We show that the MLSA originates from the stratiform response to deep convection. On short timescales, high rain events in the tropics are associated with the outward propagation of a warm anomaly in the upper troposphere, and a cold anomaly in the lower troposphere. This dipole heating response to deep convection is believed to originate from the heating profile generated by precipitating stratiform anvil clouds (Houze, 2004). Within these clouds, the condensation of water vapor, and freezing of water, generates warming. When the precipitation generated by stratiform clouds falls below cloud base (usually near the melting level), the evaporation and melting of precipitation generates cooling.

Within the tropics, the height of the melting level has been rising for the past several decades (Bradley et al., 2009). Provided the warming of the tropical atmosphere continues, and provided cloud microphysical and dynamical processes continue to anchor the lower surface of precipitating stratiform clouds to a height near the melting level, the dipolar stratiform heating profile generated by these clouds should shift to a higher altitude. This should generate an upward shift in the height of the melting level stability anomaly. Here, we use a 10 year record of high vertical resolution radiosonde measurements from the western tropical Pacific to show that the melting level stability anomaly does indeed shift to a higher altitude when the surface temperature increases. We also use model results to argue that this shift is also likely to occur in response to changes in surface temperature occurring on longer timescales.

\section{Datasets}

\subsection{Radiosondes}

Temperature profiles from radiosondes are usually not archived with sufficient vertical resolution to characterize the complex variation of lapse rate with height in the tropical lower troposphere. They also often suffer from instrumental biases which introduce uncertainties into the calculation 


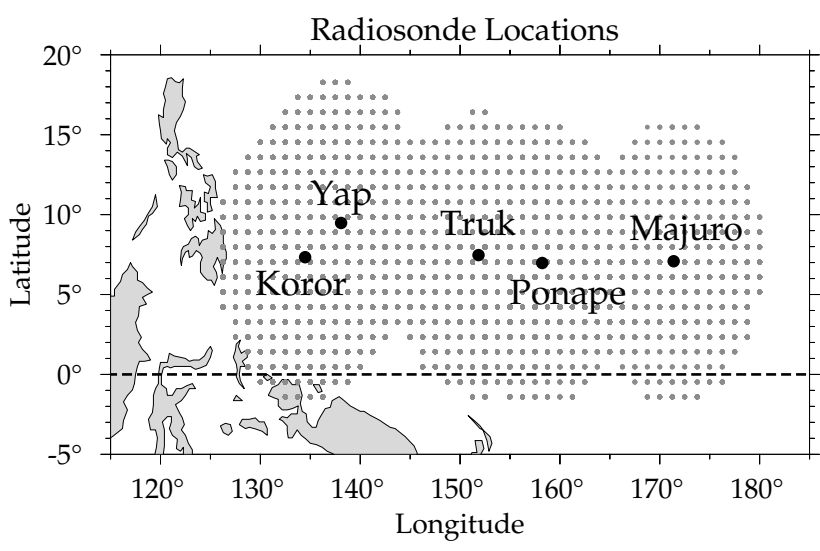

Fig. 1. A map showing the locations of the five radiosonde stations. The small gray dots refer to locations of the TRMM rain events used in the construction of the radial temperature anomaly profile shown in Fig. 2. Rain events within $1000 \mathrm{~km}$ of multiple radiosonde stations were in general used multiple times in the construction of Fig. 2.

of trends in lapse rate (Sherwood et al., 2005; Randel and Wu, 2006; Thorne et al., 2011). Here, we use an $10 \mathrm{yr}$ record (1999-2008) of homogeneous, high vertical resolution radiosonde measurements from five stations in the Western tropical Pacific, to examine the response of the tropical atmosphere to changes in surface temperature.

The radiosonde data were taken from the Stratospheric Processes and their Role in Climate (SPARC) radiosonde archive. We used data from Koror (Palau Island: $\left.7.33^{\circ} \mathrm{N}, 134.48^{\circ} \mathrm{E}\right)$, Yap Island $\left(9.48^{\circ} \mathrm{N}, 138.08^{\circ} \mathrm{E}\right)$. Truk (Moen Island: $7.47^{\circ} \mathrm{N}, 151.85^{\circ} \mathrm{E}$ ), Ponape Island $\left(6.97^{\circ} \mathrm{N}, 158.22^{\circ} \mathrm{E}\right)$, and Majuro (Marshall Island: $7.08^{\circ} \mathrm{N}$, $\left.171.38^{\circ} \mathrm{E}\right)$. The twice daily measurements were used to construct monthly mean profiles of temperature, pressure, and relative humidity on a $200 \mathrm{~m}$ vertical grid. The locations of the stations are shown in Fig. 1. The five radiosonde stations occur in a roughly linear sequence parallel to the equator stretching eastward from the Philippines, and are located within the northern branch of the Inter-Tropical Convergence Zone.

In the tropics, the timescale to reach radiative convective equilibrium is roughly equal to a month (Emanuel, 1994). The twice daily radiosonde measurements were therefore averaged to generate monthly mean temperature profiles at each site. Monthly means from the entire $10 \mathrm{yr}$ period (19992008) were then used to define the vertical profile of the monthly temperature anomaly at each site.

\subsection{Rainfall}

The Tropical Rainfall Measuring Mission (TRMM) 3B42 gridded dataset contains rainfall estimates on a $0.25^{\circ}$ grid every $3 \mathrm{~h}$ (Kummerow et al., 2000). We first averaged the rain rates to a $0.5^{\circ} \times 0.625^{\circ}$ grid box resolution. We then consid- ered rain events to occur at grid boxes where the rain rate in any 3 hour interval exceeded $36 \mathrm{~mm}$ day $^{-1}$. We then looked for rain events between 1999 and 2008 that had occurred within $1000 \mathrm{~km}$ of one of the five radiosonde stations shown in Fig. 1. If a radiosonde launch (00:00 or 12:00 GMT) occurred at the same time as a TRMM rain event, the radiosonde temperature profile was used to construct a composite anomaly pattern of the impact of high rain events on the temperature of the background atmosphere.

Deep convection couples temperature anomalies in the boundary layer to temperature anomalies in the free troposphere. One objective of this paper is to calculate the vertical variation of this temperature response, known as the amplification factor. However, in the absence of deep convection, temperature anomalies in the free troposphere should become decoupled from temperature anomalies in the boundary layer. We therefore filtered the radiosonde data to remove months in which the mean rainfall rate at each station fell below a particular threshold. To do this, we first averaged the high resolution TRMM 3B42 rainfall dataset to generate monthly mean rain rates in a $2^{\circ} \times 2^{\circ}$ box centered at each of the five radiosonde locations. We then removed from our analysis months in which the monthly mean rainfall rate fell below $3 \mathrm{~mm}$ per day.

\subsection{Climate models}

Here, we use monthly mean temperature anomalies over a 10 year period to determine the temperature response of the free troposphere to changes in temperature near the surface. This temperature response is unlikely to exactly equal the response to changes in near surface temperature that would occur on longer timescales. However, we use temperature profiles from the World Climate Research Programme's (WCRP's) Coupled Model Intercomparison Project phase 3 (CMIP3) multi-model dataset (Meehl et al., 2007) to show that the monthly response obtained from a $10 \mathrm{yr}$ record should be similar to the response that would be obtained from a longer term record.

We used monthly mean fields from six of the coupled ocean-atmosphere models participating in the CMIP3 Climate of the Twentieth Century Experiment. The forcing agents used in this experiment include greenhouse gases $\left(\mathrm{CO}_{2}, \mathrm{CH}_{4}, \mathrm{~N}_{2} \mathrm{O}\right.$, and CFC's), direct effects from sulfate aerosols, volcanoes, and solar forcings. The simulations usually start in 1850. We used 1950-2000 output from the following six models: (i) Canadian Centre for Climate Modelling and Analysis CGCM3 (CCCMA CGCM3, $3.75^{\circ} \times 3.75^{\circ}$ horizontal resolution), (ii) National Center for Atmospheric Research CCSM3 (NCAR CCSM3, $1.4^{\circ} \times 1.4^{\circ}$ horizontal resolution), (iii) Hadley Centre for Climate Prediction and Research HADCM3 (UKMO HADCM3, $3.75^{\circ} \times 2.5^{\circ}$ horizontal resolution), (iv) CSIRO Atmospheric Research MK3 (CSIRO MK3, $1.875^{\circ} \times 1.875^{\circ}$ horizontal resolution), (v) Goddard Institute for Space Studies MODEL 
E H (GISS MODEL E H, 5.0 $\times 4.0^{\circ}$ horizontal resolution), and (vi) Centre National de Recherches Météorologiques $\mathrm{CM} 3$ (CNRM CM3, $2.81^{\circ} \times 2.81^{\circ}$ horizontal resolution). All models have 17 vertical levels, except for the UKMO model which has 15 levels. Of these levels, 12 are usually in the troposphere (below $17 \mathrm{~km}$ ). Monthly mean temperature profiles from these simulations were analyzed using the same procedures used for the radiosonde data.

\section{Results}

\subsection{Radial temperature anomaly about high rain events}

The middle panel of Fig. 2 shows the impact of high rain events on the temperature of the background atmosphere. High rain events were considered to occur at grid boxes where the TRMM rain rate exceeded $36 \mathrm{~mm} \mathrm{day}^{-1}$. The horizontal axis refers to the distance between the rain event and a simultaneous radiosonde temperature profile. The top panel of Fig. 3 shows the mean radial distribution of rainfall about the high rain events used to construct the temperature anomaly pattern. The probability of a rain event occurring at a particular distance from a radiosonde profile increases with distance. The number of radiosonde profiles within each radial distance bin therefore also increases with distance. For example, there were 403 radiosonde launches within $25 \mathrm{~km}$ of a high rain event. At larger distances, there were typically between 10000 and 30000 available radiosonde profiles within each $50 \mathrm{~km}$ radial distance bin. The temperature anomaly was defined by subtracting from the observed temperature profile the monthly mean temperature profile of the appropriate year and radiosonde station. In the tropics, on short timescales, deep convective events generate a complex temperature response characterized by cooling near the surface (below $1 \mathrm{~km}$ ), cooling in the lower troposphere $(2 \mathrm{~km}-5 \mathrm{~km})$, warming in the upper troposphere $(8 \mathrm{~km}-13 \mathrm{~km})$, and cooling in the tropical tropopause layer $(14 \mathrm{~km}-17 \mathrm{~km})$ (Sherwood and Wahrlich, 1999; Mapes et al., 2006; Mitovski et al., 2010). The middle panel of Fig. 2 also shows that the spatial scale of the upper tropospheric warming is significantly larger than the spatial scale of the lower tropospheric cooling (Folkins et al., 2008). It has been argued that the lower tropospheric cooling favors the development of convective clouds in the neighborhood of deep convective events, and contributes to the observed clustering, or gregariousness, of tropical deep convection (Mapes and Houze, 1995).

The lower panel of Fig. 2 shows the change in stability $(d T / d z)$ associated with the observed temperature anomaly pattern. Deep convection tends to stabilize the surface layer (below $1 \mathrm{~km}$ ), destabilize the top of the boundary layer $(2 \mathrm{~km})$, increase the stability of the middle troposphere $(4.5 \mathrm{~km}-8 \mathrm{~km})$, and decrease the stability of the upper troposphere $(12 \mathrm{~km}-15 \mathrm{~km})$. The increase in mid-level
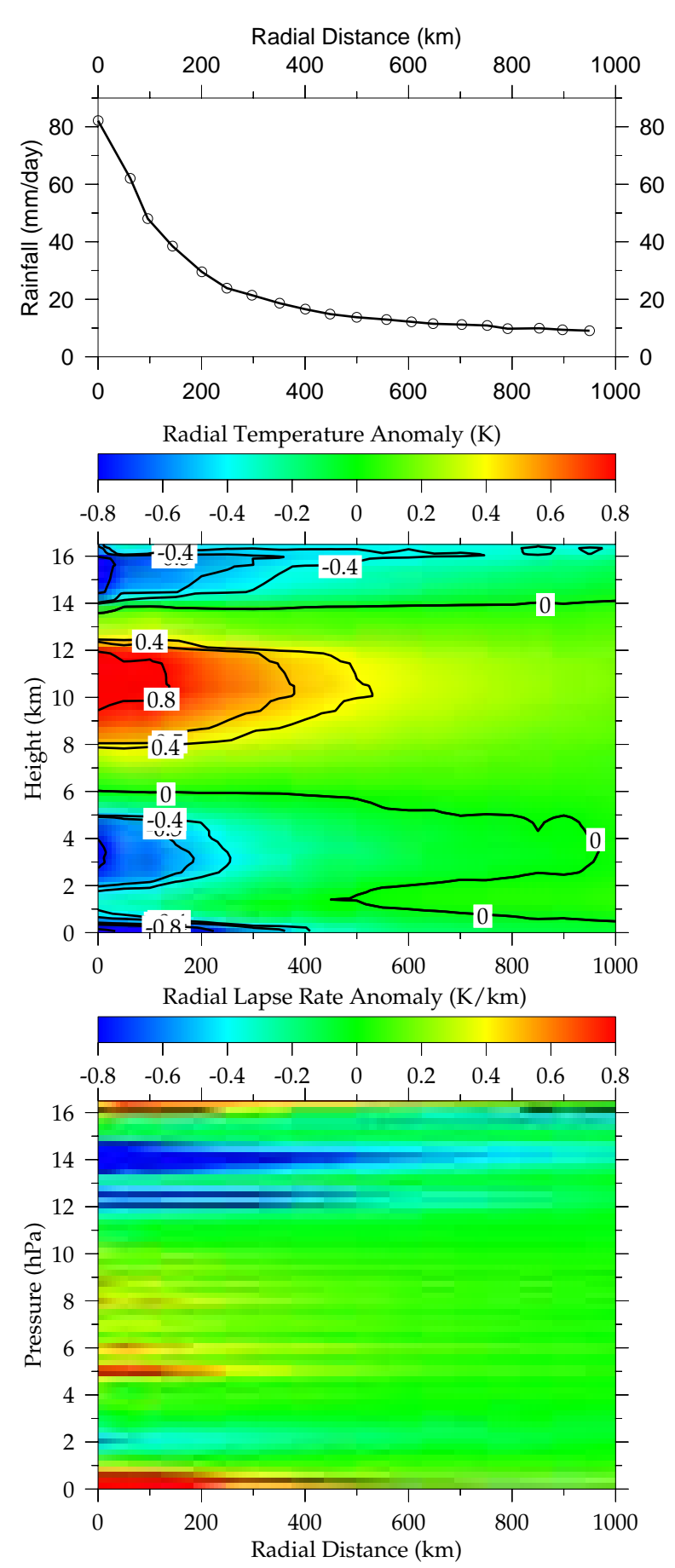

Fig. 2. (top) The mean variation in rainfall with distance from high rain events. Rain events were considered to occur at grid boxes where the rain rate in any 3 hour interval exceeded $36 \mathrm{~mm} \mathrm{day}^{-1}$. (middle) The temperature anomaly pattern associated with the high rain events. The horizontal axis refers to the distance between the rain event and the radiosonde location. (lower) The lapse rate anomaly associated with the temperature anomaly pattern shown in the middle panel. High rain events are associated with increased stability in the mid-troposphere. 


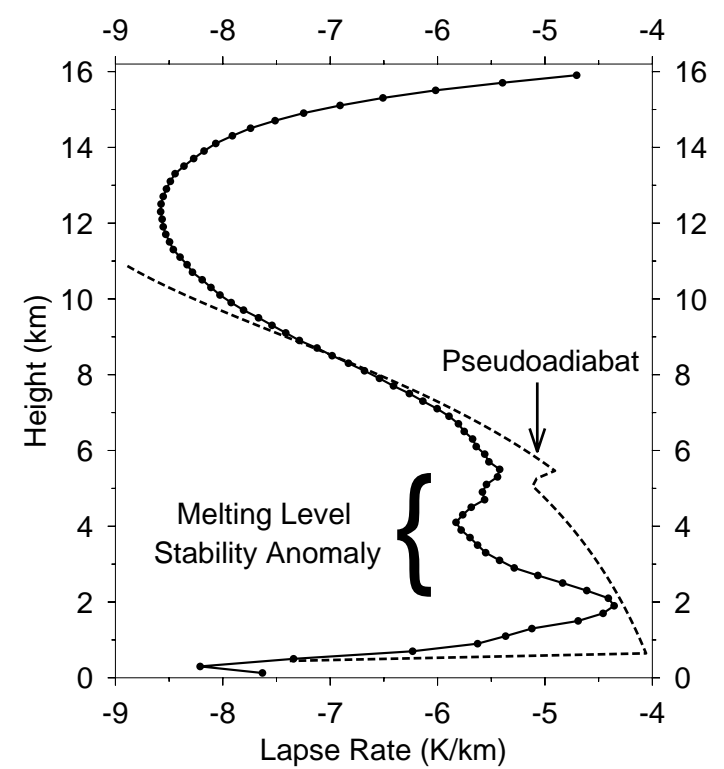

Fig. 3. The solid curve with bullets shows the mean lapse rate profile (1999-2008) of the five radiosonde stations discussed in this paper. The dashed curve shows the lapse rate profile of a parcel starting from the surface with a temperature of $299.5 \mathrm{~K}$ and relative humidity of $80 \%$, and subjected to pseudoadiabatic ascent.

stability associated with high rain events would favour the detrainment of convective clouds at mid-levels, and has been invoked to explain the existence of the cumulus congestus mode (Johnson et al., 1999; Redelsperger et al., 2002). It also provides a mechanism for spatially coupling congestus clouds to regions of active deep convection.

\subsection{Observed lapse rate}

The solid black line in Fig. 3 shows the lapse rate profile generated by averaging all monthly mean temperature profiles from the five radiosonde locations. As mentioned earlier, the mean stability profile shows local maxima at the top of the boundary layer $(\sim 2 \mathrm{~km})$, the melting level $(\sim 5.5 \mathrm{~km})$, and the tropopause $(\sim 16 \mathrm{~km})$. The dashed line in Fig. 3 shows the lapse rate generated by subjecting an air parcel at the surface with a temperature of $299.5 \mathrm{~K}$ and relative humidity of $80 \%$, to pseudoadiabatic ascent. During pseudoadiabatic ascent, all condensate is assumed to produce precipitation and is immediately removed. For temperatures larger than $0^{\circ} \mathrm{C}$, the maximum permitted vapor pressure was set equal to the saturation vapor pressure over water. For temperatures less than $0^{\circ} \mathrm{C}$, the maximum permitted vapor pressure was set equal to to the saturation vapor pressure over ice. The change to a more rapid decrease in saturation vapor pressure at the melting level increases the rate of condensational heating in the rising air parcel. This generates a slightly more stable lapse rate, and gives rise to the small notch in the lapse rate at the melting level.
Figure 3 shows that the observed lapse rate approximates a moist pseudoadiabat between $6 \mathrm{~km}$ and $10 \mathrm{~km}$. Between the top of the boundary layer $(\sim 2 \mathrm{~km})$ and the melting level $(\sim 5 \mathrm{~km})$, the lapse rate varies with altitude in a complex manner that is not usefully described as either a moist pseudoadiabat or a reversible adiabat (Mapes, 2001; Folkins, 2006). This might be viewed as surprising, if one thinks of the lapse rate profile as being determined exclusively by convective updrafts. Below the melting level, however, the mesoscale downdraft mass flux is probably comparable with the convective updraft mass flux. The mass fluxes from both processes can be expected to interact with the background stratification, and attempt to drive the environmental density toward some preferred profile. Below the melting level, it is therefore more appropriate to regard the observed lapse rate profile as a response to some combination of the buoyancy driven updraft and and downdraft mass fluxes (Folkins, 2009).

\subsection{Rainfall filtering}

As mentioned earlier, the TRMM 3B42 rainfall dataset was used to define monthly mean rainfall rates within a $2^{\circ} \times 2^{\circ}$ box centered at each of the five radiosonde locations. The top panel of Fig. 4 shows the probability distribution of the monthly mean rainfall rates at the five radiosonde stations. Monthly mean rain rates at the five radiosonde stations usually exceed $3 \mathrm{~mm} \mathrm{day}^{-1}$. However, there were occasional months when the rainfall rate was near zero.

Moist convection should couple fluctuations in monthly mean free tropospheric temperature to fluctuations in the local boundary layer temperature and humidity. It is clear from Fig. 2, however, that even on short timescales, deep convection gives rise to temperature anomalies that in the upper troposphere extend over a spatial scale of roughly $1000 \mathrm{~km}$. There will therefore be other sources of variance in monthly mean temperature in addition to local fluctuations in moist convection caused by local changes in boundary layer temperature. The relative role of local moist convection in determining the local temperature profile should, however, increase with the local rain rate.

At each radiosonde station, and for each month, we placed the $10 \mathrm{~km}$ and near surface temperature anomalies in a particular rainfall bin depending on the local monthly mean rain rate. A correlation coefficient was then calculated using all temperature anomaly pairs from a common rainfall bin. The curve with open circles in the lower panel of Fig. 4 shows that the correlation between the $10 \mathrm{~km}$ temperature anomaly and the local near surface temperature anomaly (below $1 \mathrm{~km}$ ) does indeed depend on the local rain rate. For rain rates less than $2 \mathrm{~mm}$ per day, upper tropospheric temperature anomalies are weakly correlated with near surface temperature anomalies. For rain rates larger than $2 \mathrm{~mm}$ per day, the correlation initially increases with rain rate, but then saturates at a limiting value of roughly 0.5 for rain rates larger than $7 \mathrm{mmday}^{-1}$. Monthly mean rain rates become 

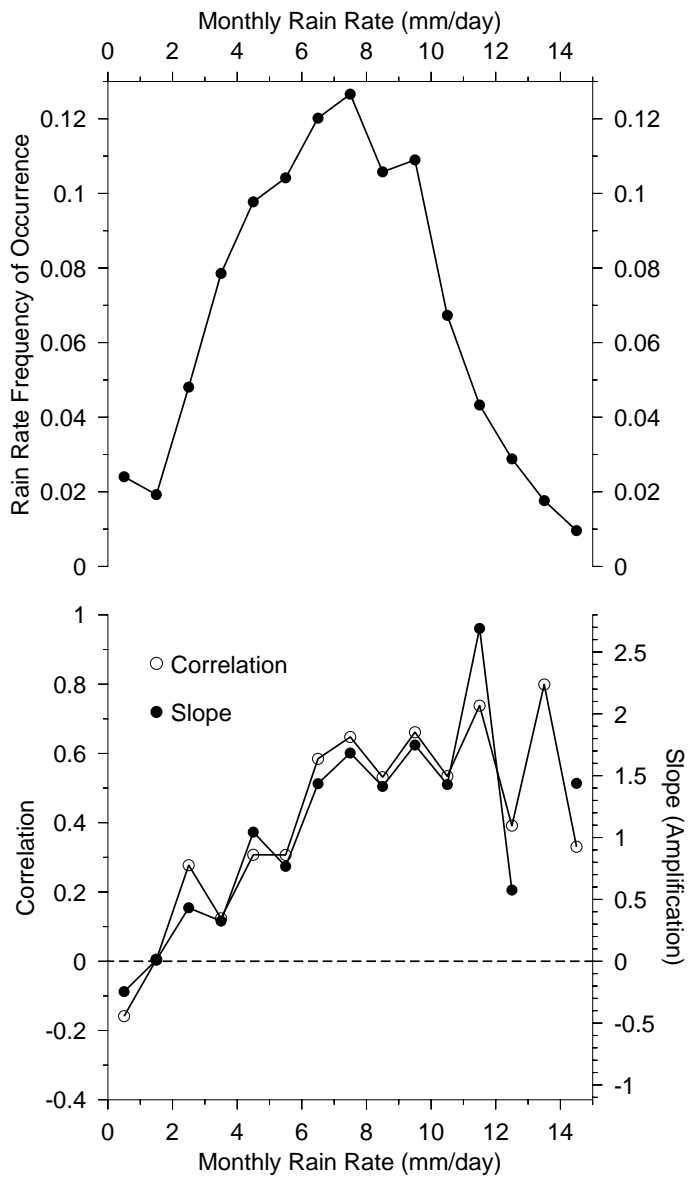

Fig. 4. (upper) This plot shows the relative frequency of occurrence of monthly mean rain rates from 1999-2008, using TRMM 3B42 rain rates averaged over a $2^{\circ} \times 2^{\circ}$ box centered at each radiosonde location. (lower) The curve with open circles shows the correlation between the near surface (below $1 \mathrm{~km}$ ) and $10 \mathrm{~km}$ monthly mean temperature anomalies of a radiosonde station, as a function of the average rain rate in a $2^{\circ} \times 2^{\circ}$ box centered at each station. The curve with open circles shows the slope of a regression of the $10 \mathrm{~km}$ monthly mean temperature anomalies against the near surface temperature anomalies, as a function of the local rain rate.

increasingly infrequent once the rain rate exceeds $10 \mathrm{~mm}$ per day. In this case, the number of temperature anomaly pairs used in the calculation of the correlation coefficient becomes correspondingly reduced, and the correlation coefficient becomes increasingly statistically uncertain.

Within each rainfall bin, we also calculated the slope of a linear regression in which the near surface temperature anomaly was used as the independent variable, and the temperature anomaly at $10 \mathrm{~km}$ was used as the dependent variable. The curve with solid circles in the lower panel of Fig. 4 shows the dependence of the slope of this regression on rain rate. At low rain rates, the slope is negative, reflecting a weak anticorrelation between the two temperature anomalies. As the rain rate increases, the slope of the regression becomes

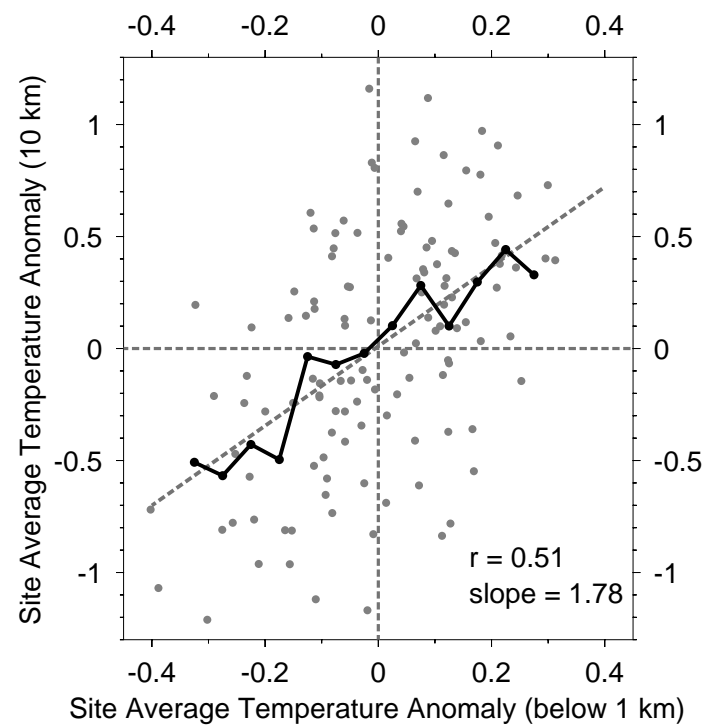

Fig. 5. The gray dots are a scatterplot of the monthly mean $10 \mathrm{~km}$ temperature anomaly versus the monthly mean surface temperature anomaly (below $1 \mathrm{~km}$ ). Each dot represents an average over all radiosonde stations in which the monthly mean rainfall rate exceeded $3 \mathrm{~mm}$ per day. The dashed line shows a best fit regression. The solid line shows the mean $10 \mathrm{~km}$ temperature anomaly calculated from grouping the surface temperature anomalies in bin sizes of $0.05 \mathrm{~K}$.

increasingly positive. This increase is consistent with an increased role for local moist convection in the upward propagation of boundary layer temperature anomalies into the upper troposphere.

\subsection{Observed amplification factor}

In Fig. 5, we show a scatterplot of the monthly mean temperature anomaly at $10 \mathrm{~km}$ versus the monthly mean temperature anomaly below $1 \mathrm{~km}$. However, rather than showing the temperature anomalies of individual stations, each point refers to an average over the five radiosonde stations for every month between 1999 and 2008. In constructing this average, we used temperature anomalies only from stations at which the local rain rate for that month exceeded a rain rate threshold of $3 \mathrm{~mm} \mathrm{day}^{-1}$. Site average temperature anomalies were defined only if the rain rate of at least three of the five stations exceeded this threshold. The dashed line shows a linear regression in which the near surface temperature anomaly was assumed to be the independent variable. The slope of this line can be interpreted as the amount by which convection amplifies the temperature response in the free troposphere to temperature anomalies near the surface.

We also calculated the upper tropospheric temperature response to changes in near surface temperature by first grouping the near surface temperature anomalies in increments of $0.05 \mathrm{~K}$, and then calculating the average $10 \mathrm{~km}$ temperature anomaly in each of these temperature bins. This response is 
represented by the solid line in Fig. 5. Although the curve is in good agreement with the regression line, there is clearly substantial variability in the upper tropospheric response to near surface temperature anomalies. This scatter can be somewhat reduced, and the slope steepened, by using a larger rain rate threshold. The scatter would also presumably be reduced if a larger number of radiosonde stations within the radiosonde region were available. It is well known, however, that rainfall anomalies can give rise to temperature anomalies in the free troposphere that extend over large distances, so that it is very likely that some of the scatter can be attributed to convective events outside the radiosonde region. The response of the free troposphere to temperature anomalies near the surface should be accurately predicted by the slope of the regression, however, provided the variability in the regional average monthly mean free tropospheric temperature due to incomplete sampling, and to dynamical events outside the radiosonde region, is symmetric in the positive and negative directions.

The black curve in Fig. 6 shows the vertical profile of the slope, or amplification factor, calculated using the same assumptions used in Fig. 5. We used site averaging to define regional changes in the near surface and free tropospheric temperature anomalies, and the near surface temperature anomaly was defined as the average anomaly between the surface and $1 \mathrm{~km}$. The amplification profile exhibits a maximum in the upper troposphere near $13 \mathrm{~km}$ and a smaller maximum in the lower troposphere near $4 \mathrm{~km}$. The secondary local maximum in the lower troposphere occurs at the same altitude as the local stability minimum shown in Fig. 3. The coincidence of these two features suggests that, in response to a surface warming, the stability below the current $4 \mathrm{~km}$ stability minimum will increase, while the stability above the current $4 \mathrm{~km}$ stability minimum will decrease. These stability changes are consistent with an upward displacement of the MLSA in a warmer atmosphere. Figure 6 also shows that warm anomalies near the surface are coupled to strong cold anomalies in the lower stratosphere.

In the calculation of the amplification factor, we assumed that the temperature anomaly below $1 \mathrm{~km}$ was the independent variable, and then calculated the temperature anomaly in the free troposphere that could be attributed to this forcing. However, during the approach to radiative convective equilibrium, it may be more appropriate to think of temperatures in the boundary layer and free troposphere as interacting with each other. For example, temperatures in the free troposphere will partially regulate the degree of convective activity through their effect on the convective available potential energy. Here, however, we want to isolate the effect of local changes in boundary layer temperature on the free troposphere. It may be possible to justify this approach on the grounds that temperatures in the free troposphere are more strongly affected by nonlocal influences ("noise") than temperatures near the surface. Temperatures in the boundary

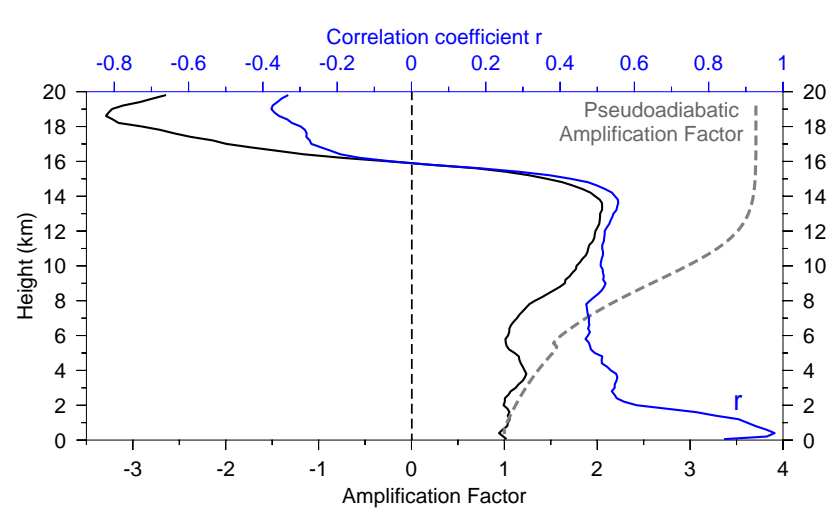

Fig. 6. The black curve shows the local temperature response associated with a $1^{\circ} \mathrm{C}$ increase in near surface (below $1 \mathrm{~km}$ ) temperature. The dashed gray curve shows the amplification profile calculated using pseudoadiabatic assumptions. The blue curve show the coefficient of correlation between the local monthly and near surface temperature anomalies.

layer are strongly coupled to the local sea surface temperature, especially on climatic timescales.

The blue curve in Fig. 6 shows the vertical profile of the correlation coefficient. As would be expected, there is a rapid decrease in the strength of the coupling with near surface temperature anomalies once you go above the boundary layer (above $2 \mathrm{~km}$ ).

The amplification factor shown in Fig. 6 can be used to calculate the change in the shape of the melting level stability anomaly associated with a $1^{\circ} \mathrm{C}$ increase in near surface temperature. At each height, we simply add the amplification factor to the annual mean temperature profile of the five radiosonde stations. The dashed gray curve in Fig. 7 shows the lapse rate generated from this warmed temperature profile. The change in the shape of the melting level stability anomaly is consistent with the existence of the secondary local maximum in the amplification factor shown in Fig. 6. While the stability increases below $4 \mathrm{~km}$, it decreases above $4 \mathrm{~km}$. This gives rise to an upward shift in the stability anomaly. It is also interesting to note that the stability maximum defining the top of the boundary layer occurs at $2 \mathrm{~km}$ in both the warmed and background temperature profiles. Increases in surface temperature therefore do not appear to be give rise to a change in the depth of the boundary layer. As a result, the overall vertical depth of the MLSA increases in response to an increase in near surface temperature.

The horizontal lines in Fig. 7 show the height of the melting level in the background (unperturbed) and warmed temperature profiles. The magnitude of the upward shift in the stability anomaly in the warmed atmosphere is roughly consistent with what would be expected from the upward displacement $(\sim 140 \mathrm{~m})$ of the melting level. 


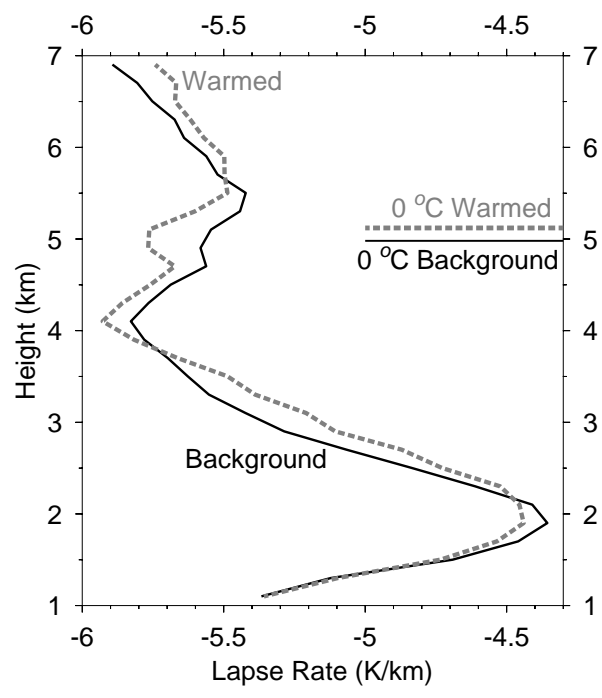

Fig. 7. The black solid curve shows the average lapse rate of the five radiosonde stations during the $10 \mathrm{yr}$ period (1999-2008). The dashed gray curve is the lapse rate of a warmed temperature profile subjected to a $1^{\circ} \mathrm{C}$ increase in near surface temperature, as described in the text. The horizontal bars denote the approximate heights of the melting level in the background and warmed atmospheres. Surface warming is associated with a shift in the lapse rate profile to a higher altitude, by an amount roughly equal to the displacement in the melting level.

\subsection{Pressure response}

Provided the surface pressure is fixed, a warming and expansion of the atmospheric column implies a shift of the atmospheric center of mass to a higher altitude. At a fixed altitude, a warming of the underlying atmosphere would therefore be associated with an increase in the overhead column mass, and an increase in local hydrostatic pressure. The vertical profile of the pressure anomaly, in response to a change in surface temperature, was calculated using the same procedure used for the temperature amplification profile. Regional mean pressure anomalies, for every month between 1999 and 2008 , were defined by averaging over the five radiosonde locations, provided the monthly mean rain rate at three of the five stations exceeded $3 \mathrm{~mm}$ day $^{-1}$. Figure 8 shows the vertical profile of the pressure response (slope) associated with a $1{ }^{\circ} \mathrm{C}$ increase in near surface temperature (below $1 \mathrm{~km}$ ). As anticipated, the pressure does indeed increase at most altitudes in response to a surface warming. However, surface warming is associated with reduced pressure below $3 \mathrm{~km}$. This is probably a dynamical effect associated with the regional scale of the warm anomalies. Suppose the column warming associated with an increase in near surface temperature was confined to the region of the five radiosonde locations. In this case, there would be no change in the pressure of height surfaces in the rest of the tropics, and warm surface anomalies within the radiosonde region would be as-

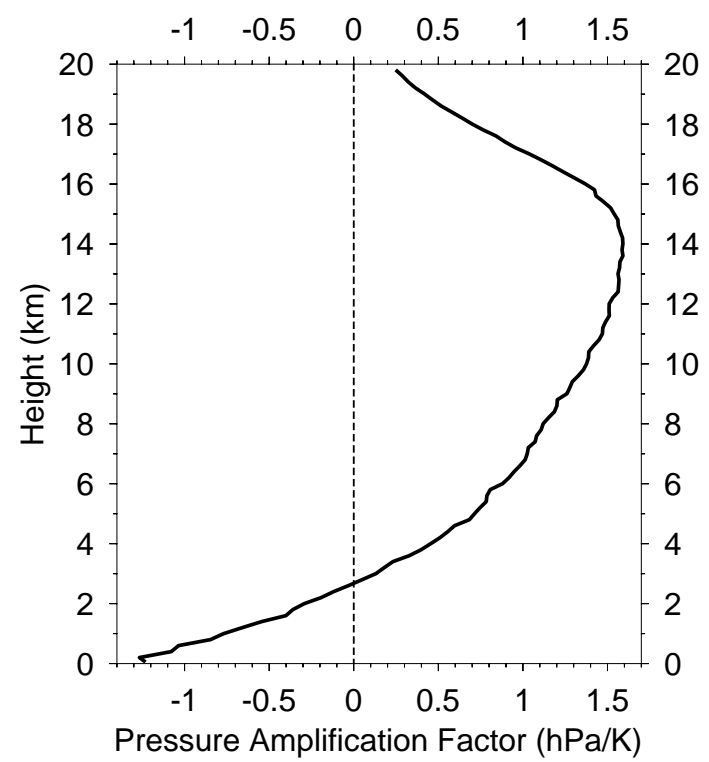

Fig. 8. The curve shows the change in pressure as a function of height associated with a $1{ }^{\circ} \mathrm{C}$ increase in near surface temperature. It was derived from a slope of a scatterplot, at each height, of the monthly mean pressure anomaly against the monthly mean near surface temperature anomaly.

sociated with high pressure anomalies aloft, relative to pressures on the same height surface outside the radiosonde region. The positive pressure anomalies within the radiosonde region would generate outward pressure gradient accelerations, and an outward divergent circulation (Maloney and Sobel, 2007) exporting mass to the rest of the tropics. This export of mass would tend to reduce surface (and lower tropospheric) pressures within the radiosonde region. The export of mass would also give rise to induced descent and subsidence warming outside the radiosonde region, and diminish subsidence heating within the radiosonde region. The existence of this dynamical response would therefore be expected to decrease the temperature amplification profile associated with a surface warming within the radiosonde region, relative to the response that would be expected if the mass circulation within the radiosonde region was self contained.

\subsection{Comparison with CMIP3 models}

This paper uses the relatively small monthly fluctuations in surface temperature within a convective region to characterize the vertical response of the atmosphere to a surface warming. We would like to determine whether the observed temperature amplification factors obtained over the $10 \mathrm{yr}$ period used here are likely to be similar to the amplification factors obtained over a longer period. To do this, we calculated the temperature amplification factors of six models from the CMIP3 multi-model dataset, using a procedure that was as similar as possible to that used for the radiosonde dataset. 


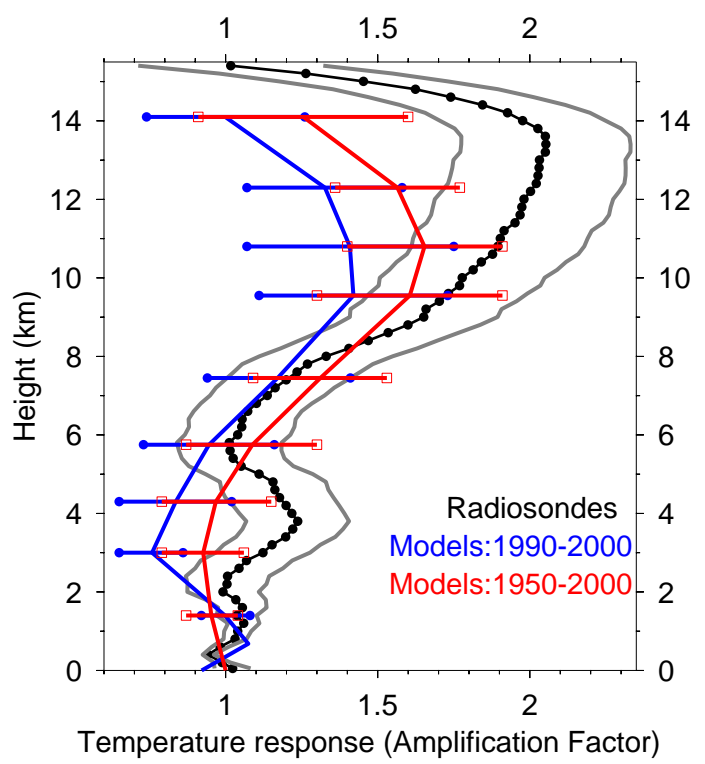

Fig. 9. The black curve shows the observed temperature amplification factor (as shown earlier in Fig. 6). The gray curves indicate the statistical uncertainty in the calculation of the amplification factor, using the standard error in the slope of the regression. The red and blue curves show the model mean 1950-2000 and 1990-2000 amplification factors, respectively. The widths of the model curves are equal to twice the average difference of the 6 model runs from the model mean.

We then compared the model amplification factors calculated from the 10 yr 1990-2000 time period with amplification factors calculated from the $50 \mathrm{yr}$ 1950-2000 time period.

For each of the six CMIP3 models, we first identified the model grid columns closest to the five radiosonde stations. We then extracted the monthly mean temperature profiles and monthly mean rainfall rate at each radiosonde location, from 1950 to 2000 . The three lowest levels in each of the six models occurred at $1000 \mathrm{hPa}, 925 \mathrm{hPa}$, and $850 \mathrm{hPa}$ (except for the second level of the UKMO model which occurred at $950 \mathrm{hPa}$ ). An average of the first two model levels approximately corresponds to an average over the lowest $1 \mathrm{~km}$, and was therefore used to define the near surface temperature anomaly. The temperature anomalies were then filtered using the same rainfall based criteria that was used for the radiosondes.

The solid blue and red curves in Fig. 9 show the model mean amplification factor profiles for the 1990-2000 and 1950-2000 time periods. Because they are defined with respect to a longer baseline period in which there is a climate trend, the 1950-2000 temperature anomalies should be larger in amplitude, and more coherently expressed in both the surface and upper troposphere, than in the 1990-2000 time period. Figure 9 shows that the temperature amplification profiles of the 1950-2000 period are, indeed, larger than those of the 1990-2000 time period. However, the choice of time

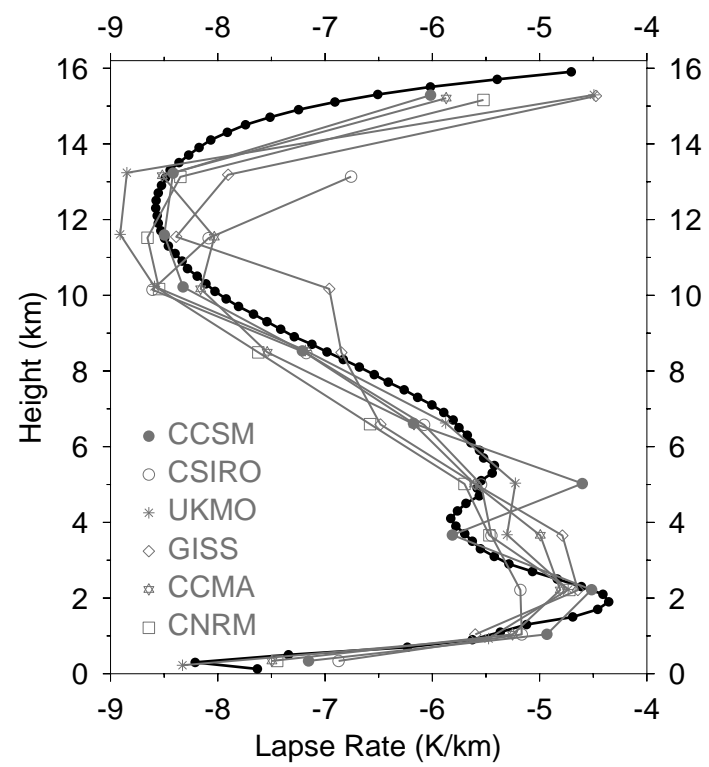

Fig. 10. The black solid curve shows the average lapse rate of the five radiosonde stations during the $10 \mathrm{yr}$ period (1999-2008), as previously shown in Fig. 3. Gray curves refer to mean lapse rates of particular models.

period does not strongly affect the shape of the amplification factor. This suggests that the shape of the observed amplification factor, calculated here from radiosonde observations over the 10 year 1999-2008 period, should be similar to the amplification factor calculated from a longer record. The model comparisons do suggest, however, that when the temperature anomalies are defined with respect to a longer reference time period, monthly fluctuations in near surface temperature are likely to be associated with larger temperature anomalies in the free troposphere.

The model mean amplification factor from the 1990 - 2000 time period exhibits significant differences from the observed amplification profile. These differences sometimes exceed the statistical uncertainty in the observed amplification profile, as indicated by the standard error in the slope of the regression (corresponding here to a $70 \%$ confidence interval). For example, the modeled amplification profiles underestimate the magnitude of the observed upper tropospheric warming, and lack the local secondary maximum in the lower troposphere. The lack of a secondary peak in the amplification factor, in the climate models, can probably be attributed to their lack of vertical resolution, and to the use of parameterizations to simulate convective processes. However, the secondary maximum also appears not to be represented in simulations using a high resolution cloud resolving model (Romps, 2011).

Figure 10 shows the annual mean lapse rate profiles of the six models, averaged over the grid columns containing the five radiosonde stations, for the 1990-2000 period. In general, the complex lapse rate variation within the melting level 
stability anomaly is not accurately captured by the models. The CCSM model does, however, exhibit a strong stability maximum near $5 \mathrm{~km}$, and the UKMO model shows a modest stability maximum at the same height.

Figure 2 indicates that the melting level stability maximum is generated by the stratiform temperature response to high rain events. The lower tropospheric cooling associated with high rain events is underestimated, or not represented, in most climate models and reanalyses (Mitovski et al., 2010). This is consistent with the tendency of the climate models shown in Fig. 10 to underestimate the strength of the observed mid-level stability maximum.

\section{Discussion}

In principle, it would be desirable to calculate the temperature amplification factor of a closed moist convective circulation. Most previous estimates of the amplification factor have therefore been based on radiosonde datasets attempting to sample the tropics as a whole. These datasets generate upper tropospheric peak amplification factors that, for the 1979-1999 period, range from near zero to larger than 2 (Santer et al., 2008). These differences appear to arise mainly from differences in the methods used to remove measurement errors. The amplification profiles calculated here are most consistent with those at the upper end of the observed range, which use the Radiosonde Observation Correction using Reanalyses (RAOBCORE) methodology (Haimberger et al., 2008).

In this paper, we have outlined a new method for calculating the temperature amplification factor. We restrict attention to a group of homogeneous, high vertical resolution radiosondes located reasonably close to each other within an actively convecting region. This method avoids some of the challenges associated with working with non-homogeneous datasets, as well as the sampling issues associated with trying to characterize temperature anomalies of the entire tropics. This approach also leads to new insights into the response of the free troposphere to near surface temperature anomalies in actively convecting regions. In particular, the existence of the secondary maximum in the lower tropospheric temperature response has not been previously observed.

It is important to appreciate, however, that the temperature amplification factors calculated here should not be considered defining characteristics of tropical convection that can be easily compared with temperature amplification factors obtained using different methods. In particular, the amplification factors calculated here can be expected to be be sensitive to the specific group of radiosonde stations used in the analysis, to the value of the rainfall threshold used to remove months considered to be non-convective, to the vertical range over which the surface temperature anomaly is defined, and to the duration of the baseline time period. Some of these considerations will apply to all observationally based esti- mates of temperature amplification factors. It is therefore important, when comparing observed and simulated temperature amplification factors, that models be sampled and analyzed in a manner that approximates the analysis of the radiosonde observations as closely as possible.

\section{Conclusions}

The mid-tropospheric stability maximum is an important aspect of the climatological temperature structure of the tropics, especially in actively convecting regions. Convective clouds which encounter enhanced stability near the melting level will tend to lose buoyancy, resulting in enhanced convective detrainment near, or somewhat above, the stability maximum. We have shown that high rain events impose a stratiform type temperature response on the background atmosphere, characterized by heating in the upper troposphere and cooling in the lower troposphere. This dipolar temperature pattern enhances the stability of the mid-troposphere, and gives rise to the observed local stability maximum. The ability of a model to reproduce the complex variation in lapse rate below the melting level is therefore likely to be a useful test of whether precipitating stratiform and downdraft processes in a model are being realistically simulated (Folkins, 2009).

There are a number of reasons for wanting to determine the response of the mid-tropospheric stability maximum to future changes in surface temperature. Any change in the height of the stability maximum is likely to be associated with a number of changes in tropical clouds and rainfall. These include changes in the height of the lower surface of precipitating stratiform clouds, in the vertical distance through which stratiform precipitation falls through cloud free air, in the efficiency of stratiform precipitation, and in the height of cumulus congestus clouds. We have attempted to determine the response of the tropical stability profile to changes in surface temperature by examining the monthly mean temperature anomalies of a group of radiosondes in the western tropical Pacific, over a 10 year period. We show that increases in surface temperature give rise to a local maximum in the temperature response near $4 \mathrm{~km}$, an altitude corresponding to a stability minimum in the current climatological temperature profile. This type of temperature response gives rise to an upward shift in the lower tropospheric stability profile, by an amount roughly consistent with the degree expected from the vertical shift in height of the melting level.

We also compared the observed temperature amplification factors with a relatively small subset (6) of the model runs stored in the CMIP3 archive. Overall, the climate model simulations examined here are in better first order agreement with the observed temperature amplification profile than most previous comparisons (Santer et al., 2005; Douglass et al., 2007). However, the climate models tend to underestimate the temperature response of the upper troposphere, 
and do not simulate the secondary maximum in the amplification factor near $4 \mathrm{~km}$. In climate models, the lack of the secondary maximum can be expected to compromise their ability to simulate future changes in the lower tropospheric stability of actively convecting regions.

Acknowledgements. This research was supported by the Natural Sciences and Engineering Research Council (NSERC). Some calculations were provided by Toni Mitovski. Glen Lesins is thanked for his input. We also acknowledge the modeling groups, the Program for Climate Model Diagnosis and Intercomparison (PCMDI), and the WCRP's Working Group on Coupled Modelling (WGCM), for their roles in making available the WCRP CMIP3 multi-model dataset. Support of this dataset is provided by the Office of Science, US Department of Energy.

Edited by: T. J. Dunkerton

\section{References}

Bradley, R. S., Keimig, F., Diaz, H., and Hardy, D.: Recent changes in freezing level heights in the tropics with implications for the deglacierization of high mountain regions, Geophys. Res. Lett., 36, L17701, doi:10.1029/2009GL037712, 2009.

Douglass, D. H., Christy, J. R., Pearsona, B. D., and Singer, S. F.: A comparison of tropical temperature trends with model predictions, Int. J. Climatol., 28, 1693-1701, doi:10.1002/joc.1651, 2007.

Emanuel, K. A.: Atmospheric Convection, Oxford University Press, New York, USA, 1994.

Folkins, I.: Convective damping of buoyancy anomalies and its effect on lapse rates in the tropical lower troposphere, Atmos. Chem. Phys., 6, 1-12, doi:10.5194/acp-6-1-2006, 2006.

Folkins, I., Fueglistaler, S., Lesins, G., and Mitovski, T.: A low-level circulation in the tropics, J. Atmos. Sci., 65, 1019-1034, 2008.

Folkins, I.: A one-dimensional cloud model with trimodal convective outflow, J. Climate, 22, 6437-6455, 2009.

Haimberger, L., Tavolato, C., and Sperka, S.: Towards elimination of the warm bias in historic radiosonde records - some new results from a comprehensive intercomparison of upper air data, J. Climate, 21, 4587-4606, doi:10.1175/2008JCLI1929.1, 2008.

Houze Jr., R. A.: Mesoscale convective systems, Rev. Geophys., 42, RG4003, doi:10.1029/2004RG000150, 2004.

Johnson, R. H., Rickenbach, T. M., Rutledge, S. A., Ciesielski, P. E., and Schubert, W. H.: Trimodal characteristics of tropical convection, J. Clim., 12, 2397-2418, 1999.

Kummerow, C., Simpson,J., Thiele, O., Barnes, W., Chang, A. T. C., Stocker, E., Adler, R. F., Hou, A., Kakar, R., Wentz, F., Ashcroft, P., Kozu, T., Hong, Y., Okamoto, K., Iguchi, T., Kuroiwa, H., Im, E., Haddad, Z., Huffman, G., Krishnamurti, T., Ferrier, B., Olson, W. S., Zipser, E., Smith, E. A., Wilheit, T. T., North, G., and Nakamura, K.: The status of the tropical rainfall measuring mission (TRMM) after two years in orbit, J. Appl. Meteorol., 39, 1965-1982, 2000.
Maloney, E. D. and Sobel, A. H.: Idealized hot spot experiments with a general circulation model, J. Climate, 20, 908-925, 2007.

Mapes, B. E. and Houze, R. A.: Diabatic divergence profiles in Western Pacific mesoscale convective systems, J. Atmos. Sci., 52, 1807-1828, 1995.

Mapes, B. E.: Water's two scale heights: The moist adiabat and the radiative troposphere, Q. J. Roy. Meteorol. Soc., 127, 23532366, 2001.

Mapes, B. E., Tulich, S., Lin, J., and Zuidema, P.: The mesoscale convection life cycle: Building block or prototype for large-scale tropical waves?, Dynam. Atmos. Ocean., 42, 3-29, 2006.

Meehl, G. A., Covey, C., Delworth, T., Latif, M., McAvaney, B., Mitchell, J. F. B., Stouffer, R. J., and Taylor, K. E.: The WCRP CMIP3 multi-model dataset: a new era in climate change research, B. Am. Meteorol. Soc., 88, 1383-1394, 2007.

Mitovski, T., Folkins, I., K. von Salzen, and M. Sigmond: Temperature, relative humidity, and divergence response to high rainfall events in the tropics: Observations and models. J. Clim., 23, 3613-3625, 2010.

Randel, W. J. and Wu, F.: Biases in stratospheric and tropospheric temperature trends derived from historical radiosonde data, J. Climate, 19, 2094-2104, 2006.

Redelsperger, J. L., Parsons, D. B., and Guichard, F.: Recovery processes and factors limiting cloud-top height following the arrival of a dry intrusion observed during TOGA-COARE, J. Atmos. Sci, 59, 2438-2457, 2002.

Romps, D.: Response of tropical precipitation to global warming, J. Atmos. Sci., 68, 123-139, 2011.

Santer, B. D., Wigley, T. M. L., Mears, C., Wentz, F. J., Klein, S. A., Seidel, D. J., Taylor, K. E., Thorne, P. W., Wehner, M. F., Gleckler, P. J., Boyle, J. S., Collins, W. D., Dixon, K. W., Doutriaux, C., Free, M., Fu, Q., Hansen, J. E., Jones, G. S., Ruedy, R., Karl, T. R., Lanzante, J. R., Meehl, G. A., Ramaswamy, V., Russell, G., and Schmidt, G. A.: Amplification of surface temperature trends and variability in the tropical atmosphere, Science, 309, 15511556, doi:10.1126/science.1114867, 2005.

Santer, B. D., Thorne, P. W., Haimberger, L., Taylor, K. E., Wigley, T. M. L., Lanzante, J. R., Solomon, S., Free, M., Gleckler, P. J., Jones, P. D., Karl, T. R., Klein, S. A., Mears, C., Nychka, D., Schmidt, G. A., Sherwood, S. C., and Wentz, F. J.: Consistency of modeled and observed temperature trends in the tropical troposphere, Int. J. Climatol., 28, 1703-1722, doi:10.1002/joc.1756, 2008.

Sherwood, S. C. and Wahrlich, R.: Observed evolution of tropical deep convective events and their environment, Mon. Weather Rev., 127, 1777-1795, 1999.

Sherwood, S. C., Lanzante, J., and Meyer, C.: Radiosonde daytime biases and late 20th Century warming, Science, 309, 1556-1559, doi:10.1126/science.1115640, 2005.

Thorne, P. W., Brohan, P., Titchner, K. A., McCarthy, M. P., Sherwood, S. C., Peterson, T. C., Haimberger, L., Parker, D. E., Tett, S. F. B., Santer, B. D., Fereday, D. R., and Kennedy, J. $\mathrm{J} .:$ A quantification of uncertainties in historical tropical tropospheric temperature trends from radiosondes, J. Geophys. Res., 116, D12116, doi:10.1029/2010JD015487, 2011. 